\title{
Lesions of Periaqueductal Gray Dissociate-Conditioned Freezing From Conditioned Suppression Behavior in Rats
}

\author{
Prin Amorapanth, ${ }^{1}$ Karim Nader, ${ }^{1,2}$ and Joseph E. LeDoux \\ Center for Neural Science \\ New York University \\ New York, New York, 10003 USA
}

\begin{abstract}
It is commonly assumed that suppression of an ongoing behavior is an indirect measure of freezing behavior. We tested whether conditioned suppression and freezing are the same or distinct conditioned responses. Rats were trained to press a bar for food and then given fear-conditioning sessions in which a tone was paired with a foot shock (two pairings a day for 2 days). They then received either sham or electrolytic lesions of the periaqueductal gray (PAG). Post-training PAG lesions blocked freezing to the conditioned stimulus (CS), but had no effect on the suppression of operant behavior to the same CS. Thus, conditioned suppression and freezing, which both cause a cessation in activity, appear to be mediated by separate processes.
\end{abstract}

\section{Introduction}

One of the most prominent behavioral responses elicited in threatening situations is the cessation of ongoing behavior (Marks 1987). In an enclosed environment, presentation of a conditioned stimulus (CS) that predicts the occurrence of a noxious unconditioned stimulus (US) causes the cessation of exploratory behavior-exploration is replaced by freezing (Blanchard and Blanchard 1969; Blanchard and Blanchard 1972; Bolles and Collier 1976). The search for the underlying mechanisms mediating this form of learning has

\footnotetext{
${ }^{1}$ These authors contributed equally to this work.

${ }^{2}$ Corresponding author.
}

been one of the most intense in the field of learning and memory. If the CS is a tone, information arrives in the amygdala either directly from the thalamus or indirectly via the auditory cortex (LeDoux et al. 1990b; Turner and Herkenham 1991; Mascagni et al. 1993; Romanski and LeDoux 1993). CS and US information converge onto single neurons in the lateral nucleus of the amygdala (LA) (Romanski et al. 1993). This is the putative site of plasticity mediating the acquisition of fear learning (LeDoux et al. 1990a; Quirk et al. 1995; McKernan and Shinnick-Gallagher 1997; Muller et al. 1997; Rogan et al. 1997). Lesions or inactivation of the LA block the acquisition and expression of fear conditioning (LeDoux et al. 1990a; Muller et al. 1997). The LA then relays information to the central nucleus of the amygdala (CE) either directly or indirectly via the basal nucleus (B) (Pitkänen et al. 1997). Lesions of the CE block the expression of the various conditioned fear responses (Kapp et al. 1979; LeDoux et al. 1988; Roozendaal et al. 1991; Campeau and Davis 1995; Walker and Davis 1997). Divergent projections from the CE to brainstem areas control the expression of the individual responses. For example, projections from the CE to the lateral hypothalamus are thought to mediate conditioned autonomic changes whereas CE projections to the periacqueductal gray (PAG) mediate freezing behavior (LeDoux et al. 1988).

Although an examination of the mechanisms mediating freezing has been instrumental in delineating the neural systems mediating this fear conditioning, psychologists traditionally have used a conditioned emotional response (CER) as a tool to examine the psychological nature of this aversive Pavlovian association. In this case animals are actively engaged in an appetitive task such as bar pressing for food, and presentation of a fear-conditioned CS causes the cessation or decrease of lever pressing (Estes and Skinner 1941). What remains

LEARNING \& MEMORY 6:491-499 @ 1999 by Cold Spring Harbor Laboratory Press ISSN1072-0502/99 \$5.00

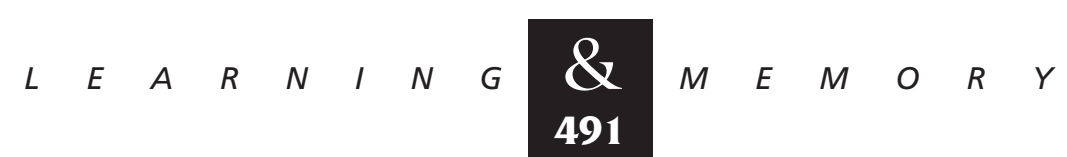


unknown, however, is whether suppression of ongoing behavior and freezing are the same or distinct responses.

One theory that has been proposed to account for the nature of suppression observed in the CER paradigm is the response competition hypothesis (Kamin 1965; McAllister and McAllister 1971). This hypothesis states that on presentation of a CS, the subject exhibits a decrease in operant behavior because the CS elicits a defensive behavioral response that is incompatible with the operant response. The main candidate competing behavior accounting for suppression is freezing. The conclusion that freezing competes with the operant response is based on findings demonstrating a high correlation between CS-elicited freezing and conditioned suppression (Bouton and Bolles 1980; Mast et al. 1982) and little correlation between other conditioned responses, such as between autonomic changes and suppression (De Toledo and Black 1966). In further support of the response competition hypothesis are the findings that similar neurobiological manipulations affect both responses. Specifically, lesions of the LA and CE have been shown to block both the suppression observed in the CER paradigm and freezing (Thompson and Schwartzbaum 1964; LeDoux et al. 1990a; Killcross et al. 1997).

Two points need to be made with regards to the above arguments. First, given that freezing is defined as immobility, then freezing must be sufficient to cause suppression. By definition an animal cannot be immobile and bar press at the same time. However, this does not tell us whether freezing is necessary for suppression. Second, although lesions of the CE block both suppression and freezing, it is possible that the CE projects to distinct areas of the brain to mediate both behaviors. Thus, we directly tested whether freezing and suppression are the same or distinct conditioned responses. This issue is important both with regards to extending our understanding of how the fear system in the brain is organized and with regards to how we compare the results of studies using freezing and conditioned suppression as responses.

Considerable evidence suggests that freezing is mediated by projections from the CE to the PAG region of the midbrain. Lesions of the PAG in general block both freezing behavior and escape responding from noxious stimulation (Lyon 1964; Halpern 1968; Liebman et al. 1970). More selective lesions localized to the ventral portions (Liebman et al. 1970; Fanselow 1991) block CS-elicited freez- ing. Additionally, lesions of the PAG that block conditioned freezing leave other conditioned responses such as autonomic changes unaffected (LeDoux et al. 1988). This has led to the suggestion that the vPAG is an output nucleus responsible for mediating the specific conditioned response of freezing and is not involved in processes such as learning and memory (LeDoux 1995). It should be noted, however, that under some conditions, lesions of the dorsal portion of the PAG have been demonstrated to affect learning (De Oca et al. 1998).

To test whether freezing and suppression are different measures of the same process, we examined the effects of PAG lesions on performance in a CER task. An off-baseline CER paradigm was used in which fear conditioning and operant training took place in distinctively different environments to ensure that the observed suppression was due specifically to the fear responses elicited by the CS. To maximize the sensitivity of our paradigm, we used a fear-conditioning procedure that resulted in an intermediate degree of suppression, thus avoiding any confounds in the interpretation caused by ceiling or floor effects, as such effects would obscure qualitative differences in suppression. Furthermore, to verify behaviorally the effectiveness of the lesions, we also assayed conditioned freezing. If the response competition model is correct, and competition is occurring between freezing and ongoing operant behavior, then lesions of the PAG that block conditioned freezing should result in a concomitant loss of suppression. On the other hand, if lesions of the PAG block freezing but not suppression, then these two behaviors must represent distinct conditioned responses.

\section{Materials and Methods}

\section{ANIMALS}

Studies were conducted using male SpragueDawley rats weighing 275-300 grams ( $n=9$ paired/ lesion, $n=10$ paired/sham, $n=8$ unpaired/sham ) at the beginning of the experiment. The animals were housed individually in clear plastic cages with free access to water. The housing area was thermally controlled at $78^{\circ} \mathrm{F}$, sealed to sunlight, and maintained on a 12-hr dark-light fluorescent light cycle with lights on at 7 a.m. During training for the CER component of this experiment, all animals were food-deprived and maintained at $85 \%$ of their initial body weight.

$$
\begin{array}{lllllllllllllll} 
& E & A & R & N & I & N & G & \begin{array}{r}
\boldsymbol{Q} \\
492
\end{array} & M & E & M & O & R & Y
\end{array}
$$




\section{SURGERY}

Rats were injected with 0.15 cc atropine intraperitoneally (i.p.), anesthetized with Nembutal (i.p., $0.1 \mathrm{cc} / 100$ gram body weight, $50 \mathrm{mg} / \mathrm{ml}$ ), and placed in a stereotaxic frame. The cranium was exposed and four burr holes were drilled using a dental drill. A stainless steel, monopolar electrode insulated with epoxy to within $200 \mu \mathrm{m}$ of the tip was lowered through an incision in the dura to the target brain area. Lesions were made by passing positive current $(0.5 \mathrm{~mA}, 10 \mathrm{sec})$ through the electrode at each site. Coordinates for bilateral PAG lesions were obtained from previous studies where freezing was blocked (LeDoux et al. 1988; Fanselow 1991). The anterior-posterior (AP), medial-lateral (ML), and dorsal-ventral (DV) coordinates were computed relative to bregma. The four lesion sites for the PAG were made at AP -7.2 and 8.0, ML \pm 0.6 , and DV -6.4. Animals in the sham lesion group had identical electrode placements with the exception that the DV coordinate was -5.4 and no current was passed through the electrode.

Following completion of surgery, the wound was closed and the animal was placed in its home cage, which rested under a heat lamp. After recovery from surgery, the animal was returned to the animal housing area and was allowed to recover undisturbed for a one-week period.

\section{APPARATUS}

The apparatus consisted of two fear-conditioning boxes (Coulbourn Instruments) and four operant-conditioning chambers (Med. Associates, Inc.), both with shock-grid flooring and Plexiglas ceilings and fronts.

The fear conditioning chambers were each housed in sound-attenuating chambers. Presentation of the CS and US was controlled by a frequency generator and output board from Coulbourn Instruments, which were controlled by an IBM-XT computer.

Each operant-conditioning chamber was housed in a separate sound-attenuating box. Illumination was provided by a light centered in the top of the front wall. The chambers were equipped for automatic presentation of delivery of $45 \mathrm{mg}$ Noyes food pellets into a recessed food cup. The CS (the 20 -sec presentation of a constant $10-\mathrm{kHz}$ tone, rise time $10 \mathrm{msec}$ ) was presented through a speaker located above the food cup. The CS was set at an intensity of $75 \mathrm{~dB}$ and the background noise (pro- duced by a fan in the chamber, in addition to ambient room noise) had an intensity of roughly 62 dB. Presentation of the CS and monitoring of the lever presses was controlled by a Gateway 2000 P5-60 computer running MED-PC.

\section{PROCEDURE}

The animals were initially food deprived to $85 \%$ of their starting body weight and trained to press a bar in the operant-conditioning chambers during seven daily 30-min sessions. For the first two sessions the rats' bar presses were reinforced on a fixed ratio of 1 (FR1), when every bar press produced reward. The reinforcement schedules were gradually made more stringent until the last 2 days of training, when all rats were reinforced on a 30 -sec variable interval schedule of reinforcement (VI30). After the last operant-training day, rats were given food and water ad libitum in their home cages and allowed to recover to normal body weight. Once normal body weight had been regained two groups of rats received paired and a third group received unpaired fear conditioning in a distinct conditioning chamber located in another room. The training procedure for paired presentation of the conditioned and unconditioned stimuli has been described in detail previously (Phillips and LeDoux 1992; Morgan et al. 1993). Briefly, on day 0 of conditioning, rats were placed individually in the fear-conditioning chamber and allowed to habituate to the conditioning chamber for $20 \mathrm{~min}$ and returned to their home cage. The next 2 days (days 1 and 2) classical conditioning trials began (two trials per day, 2 days). The conditioned stimulus, a $10-\mathrm{kHz}, 75-\mathrm{dB}$ tone, was presented for $20 \mathrm{sec}$ through a speaker mounted on the front panel of the chamber. The unconditioned stimulus consisted of a 0.5 -sec (0.5-mA) scrambled shock through the floor grid that coterminated with the tone CS. The intertrial interval was an average of $120 \mathrm{sec}$, with a range of $90-150 \mathrm{sec}$. Training sessions lasted between 5 and $10 \mathrm{~min}$.

Unpaired fear conditioning entailed presenting CS on the same schedule as the paired procedure. Presentation of the US, however, was presented pseudo-randomly such that the order of stimulus presentation was US/CS/US/CS, with the US not occurring within $60 \mathrm{sec}$ of CS termination.

Two days following fear conditioning, the animals underwent surgery. After completion of surgery, the animals were allowed to recover for 1 week, during which they had free access to food

$$
\begin{array}{lllllllllllllll} 
& E & A & R & N & I & N & G & \begin{array}{r}
\boldsymbol{Q} \\
493
\end{array} & M & E & M & O & R & Y
\end{array}
$$




\section{Amorapanth et al.}

and water. One group of rats (group paired/lesion) that had been trained with paired fear conditioning received electrolytic lesions of the PAG. The remaining two groups received sham lesions (groups unpaired/sham and paired/sham). After the recovery period, the effectiveness of the lesions was verified behaviorally by presenting the CS once to all animals $2 \mathrm{~min}$ after they were placed in the fear-conditioning chamber. The number of seconds spent freezing during CS presentation was determined by observing the behavior of the rats in the conditioning box through a peephole and with stopwatches to measure the total amount of freezing. The experimenter was blind to the subject's surgical and training history.
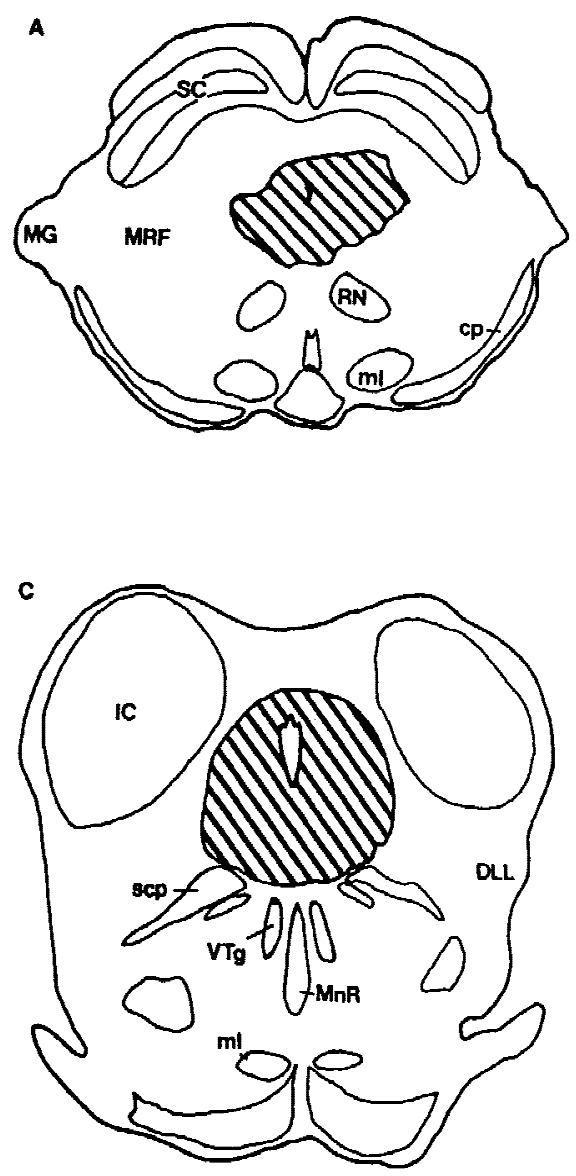

Following this, all animals were again food deprived to $85 \%$ of initial body weight and given several additional practice sessions on the VI30 schedule in the operant chambers until their baseline rates of responding were stable. Testing occurred on the next day during a 30-min session in the operant-conditioning chamber. The CS was presented without shock starting after the tenth minute of the session.

Suppression ratios (SRs) were calculated according to the following formula: $S R=[(\mathrm{CS} /$ preCS) + CS], where CS is the bar-pressing rate during the 20-sec tone and preCS is the bar-pressing rate during the $20 \mathrm{sec}$ prior to the tone (Kamin 1965).
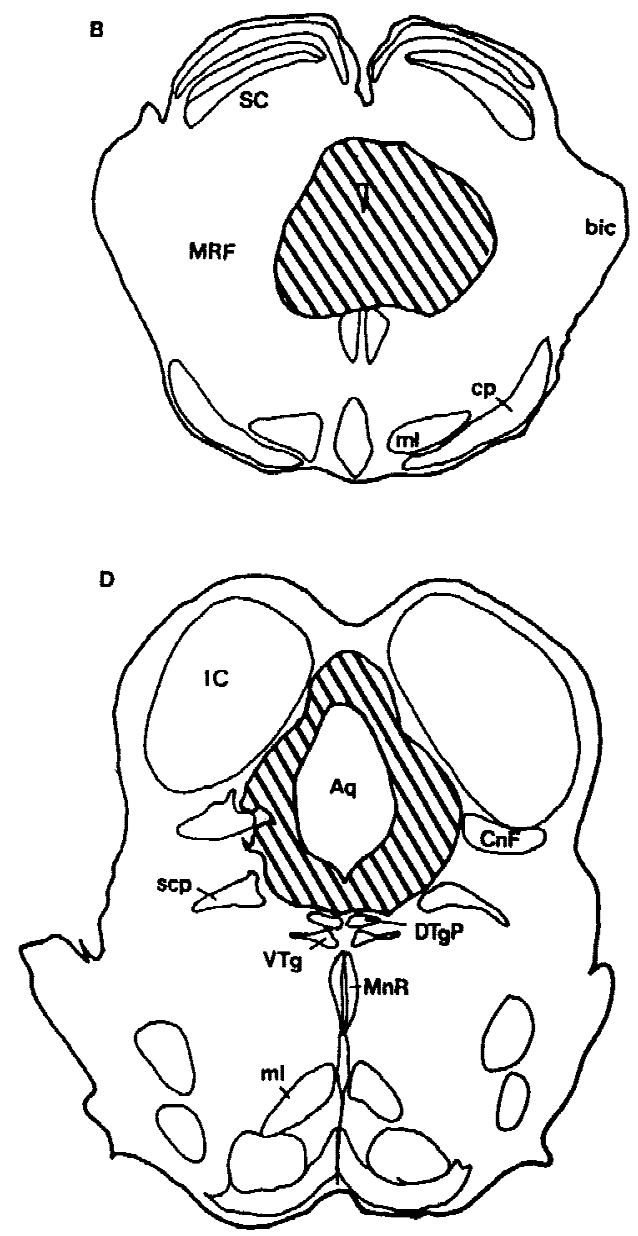

Figure 1: A schematic representing coronal sections through the rostrocaudal extent of the PAG lesions (A-D, rostral to caudal). The hatched areas show representative examples of PAG lesions made in this study. (Aq) Aqueduct; (bic) brachium inferior colliculus; (CnF) cuneiform; (cp) cerebral peduncle; (DLL) dorsal nucleus of lateral lemniscus; (DTgP) dorsal tegmental nucleus, pericentral; (IC) inferior colliculus; (MG) medial geniculate body; (ml) medial lemniscus; (MnR) median raphe; (MRF) midbrain reticular formation; (RN) red nucleus; (SC) superior colliculus; (scp) superior cerebellar peduncle; (VTg) ventral tegmental nucleus.

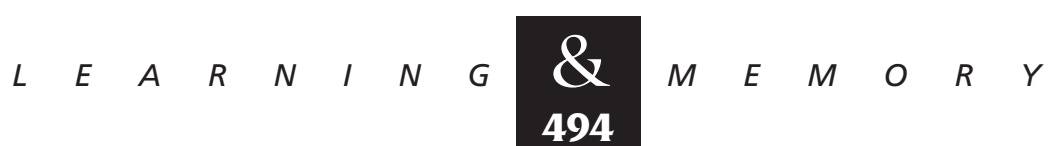




\section{HISTOLOGY}

Following completion of the behavioral studies, animals were deeply anesthetized with Nembutal $(0.5 \mathrm{cc}, 50 \mathrm{mg} / \mathrm{ml})$ and transcardially perfused with physiological saline and $10 \%$ buffered formalin. The brains were stored in 30\% sucrose in formalin postfix solution and sectioned on a microtome at $50 \mu \mathrm{m}$. Every other section was collected on a slide and stained with cresyl violet. Sections were examined and images digitally captured under bright-field microscopy using Stereo Investigator (v. 3.16, MicrobrightField, Inc.).

\section{Results}

Typical lesions are illustrated in Figures 1 and 2. The lesions usually engulfed the ventral PAG and extended to the dorsal edge of the dorsal tegmentum, with slight damage to the lateral portions of the PAG. Portions of the raphe nuclei were lesioned as well.

Mean times spent freezing for all groups are shown in Figure 3A. An analysis of variance (ANOVA) comparing the freezing scores between groups (unpaired/sham, paired/sham, and paired/ lesion) revealed a significant effect of group, $F(2$, $24)=5.6, P<0.05$. Newman-Keuls post hoc analysis with group as the factor revealed that paired/ sham animals froze significantly more than rats in either unpaired/sham or paired/lesion groups ( $P$ values $<0.05)$. Furthermore, the freezing scores of rats in groups unpaired/sham and paired/lesion were comparable $(P>0.05)$. Two conclusions arise from these results. First, freezing was the result of the acquisition of an association between the CS and US in the paired groups. Second, the PAG lesions were effective in reducing freezing, replicating previous findings (e.g., LeDoux et al. 1988; Fanselow 1991).

The suppression data are shown in Figure 3B. An ANOVA on the suppression scores between the groups (unpaired/sham, paired/sham, and paired/ lesion) again indicated an effect of group, $F(2$, $24)=8.0, P<0.05$. Post hoc analysis using a Newmans-Keuls test with group as the factor demonstrated that rats in group paired/sham and paired/ lesion suppressed operant responding to the CS significantly more than rats in unpaired/sham $(P$ value $<0.05)$. Furthermore, there was no significant difference in suppression ratios between groups paired/sham and paired/lesion. Freezing scores during suppression were 0 for all groups. It can be concluded that suppression of ongoing behavior was due to an associative, as opposed to a nonassociative, relation between the CS and US. In addition, lesions of the PAG that impaired freezing behavior had no effect on suppression of instrumental behavior.

The suppression data reported above were not confounded by differences in baseline responding. There were no differences between any of the groups in their preCS rates of bar pressing (data not shown, paired/sham $=9 \pm 0.7$, unpaired/ sham $=7.6 \pm 1.1$, and paired/lesioned $=8.5 \pm 1.4$, $F(2,24)=0.4, P>0.05)$. Thus, suppression of operant behavior was not affected significantly by lesions of the PAG.

\section{Discussion}

Lesions of the PAG dissociate the classical fear
A

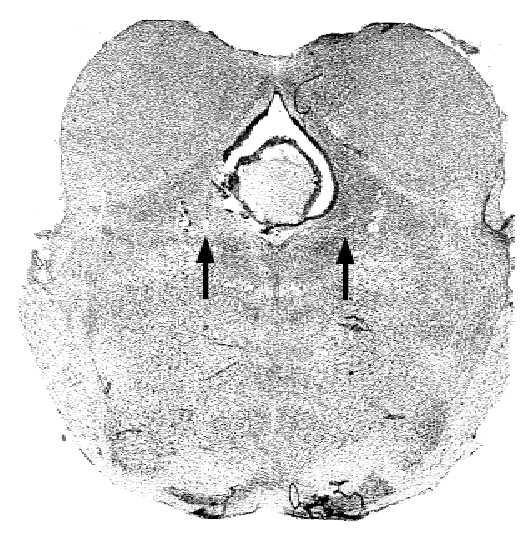

B

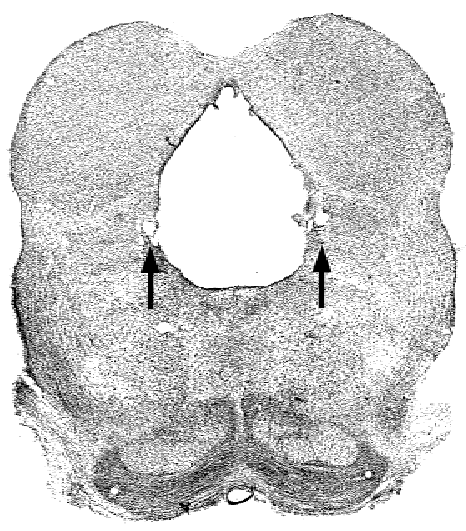

Figure 2: Coronal image of Sham $(A)$ and PAG $(B)$-lesioned animals. (Arrowheads) The tips of the electrodes.

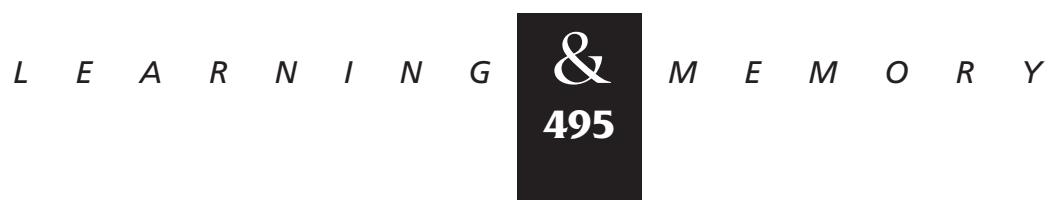


responses of freezing and suppression. Specifically, lesions of the PAG that produced significant decreases in conditioned freezing had no effect on the suppression seen in a CER paradigm. Furthermore, suppression was the result of an associative as opposed to nonassociative process, as rats that received unpaired fear conditioning demonstrated significantly less suppression compared with rats that had received paired CS and US presentations. These findings are in direct contradiction to the response competition hypothesis, which posits that suppression of an operant behavior is an indirect assay of freezing. Thus, distinct processes must mediate the conditioned responses of freezing and suppression. This conclusion is also supported by behavioral evidence demonstrating that visual CSs, which elicit less freezing than auditory CSs, cause more suppression that auditory CSs (Kim et al. 1996). This does not imply that suppression is a poor index of fear, rather, it suggests

A

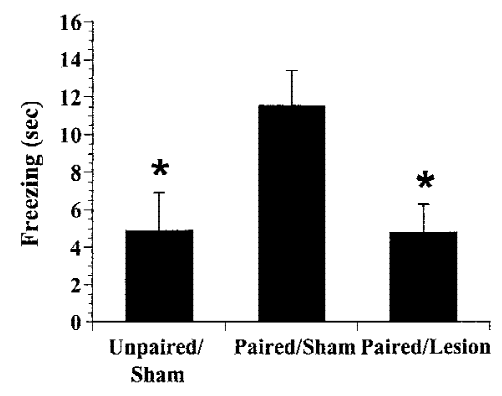

B

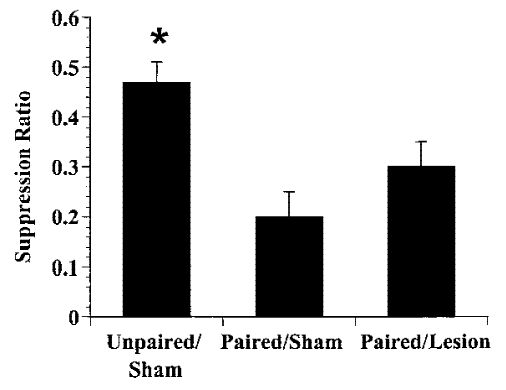

Figure 3: (A) Effects of post-training lesions of the PAG on conditioned freezing behavior. $(B)$ Effect of lesions of PAG on conditioned suppression. The suppression ratio is calculated as CS/preCS + CS, where preCS is the number of presses in a 20-sec period prior to CS onset and CS is the number of presses during the 20-sec CS. The first name of the group refers to whether rats received paired or unpaired fear conditioning. The second word refers to whether animals received electrolytic or sham lesions of the PAG. Bars represent group mean $\pm{ }^{+}$s.e.m. ${ }^{-}$. that suppression may be a distinct conditioned response to fear-eliciting stimuli.

In the present study, freezing was tested prior to suppression. Thus, it is possible that our results were influenced by an order effect. For example, the freezing extinction test could have led to differential extinction of the two behaviors. Although possible, this does not influence the interpretations of the study. The response competition hypothesis states that suppression is simply an indirect measure of freezing. Therefore, it does not predict an order effect that would lead to any differential extinction or expression of these two behaviors because freezing and suppression are hypothesized to be the same thing. If there were differential extinction or differential expression, then this would only support our claim that freezing and suppression are different behaviors.

A second consideration is the fact that animals were tested for freezing in an independent test session while food sated. Thus, this may confound our results in some way. First, in our paradigm there was no detectable freezing during the suppression (all animals had scores of 0 ). Second, we feel that the absence of freezing during suppression is not informative. Specifically, it is quite conceivable the freezing mechanisms were engaged, however, they could not outcompete the bar-pressing response. In this case, activation of the freezing mechanisms was not strong enough to induce complete immobility but was strong enough to reduce bar pressing. Thus, although the freezing mechanisms are responsible for suppression in this scenario, the absence of freezing would lead to the false interpretation that freezing is not necessary for suppression. By testing animals in an alternate environment where there is no history of food being present while food sated (to reduce locomotor activity) we are maximizing the level of observable freezing. This is the most sensitive way to assay for freezing including any residual freezing in the lesioned groups. In fact, this experimental design biases the results towards the response competition hypothesis by maximizing the sensitivity of our paradigm to freezing.

Furthermore, the fact that animals were tested for freezing while food sated whereas suppression was tested while the amimals were food deprived could have led to state-dependent effects. Speaking against this interpretation, however, are findings that there was no effect on suppression in the lesioned group. Animals were conditioned sated and then tested on suppression while food deprived. If

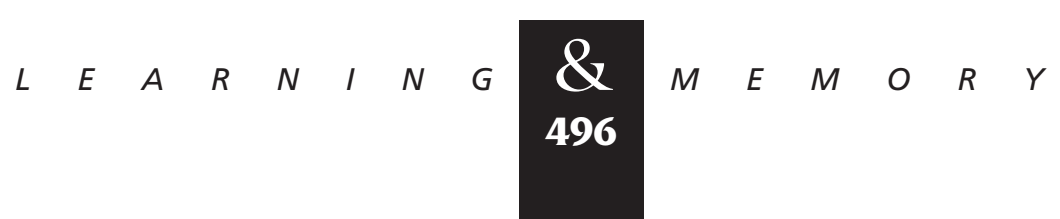


the state change interacted with the lesions to impair the recall of the association, then suppression should have been impaired. However, both the sham/paired and lesion/paired groups showed comparable suppression. Furthermore, states such as food deprivation are thought to act analogously to contexts when they contribute to an association. Changes in contexts have little effect on excitatory conditioning using conditioned suppression (see Bouton 1994).

If suppression of an operant behavior is not the result of response competition between conditioned freezing and operant responding, then what is the qualitative nature of this type of cessation of behavior? One possibility is that some other conditioned response aside from freezing competes with ongoing operant behavior. In this case, the suppression would still be qualitatively due to response competition, however, the competing response would be something other than freezing. Although possible, this hypothesis seems unlikely, given that freezing behavior is the defensive behavior that typically has the best correlation with suppression (see Introduction).

Our finding that PAG lesions block freezing but not conditioned suppression is consistent with the standard view of the neural pathways underlying the expression of conditioned fear. That is, different conditioned fear responses are mediated by different projections of the CE (Davis 1994; LeDoux 1996). An implication of these results is that something about the state of the animals in a CER paradigm causes the fear system to change the strategy used to halt behavior. During exploration in an enclosed environment, freezing replaces exploration. Once engaged in active goal-directed behavior, although freezing is still present, the nature of the cessation of behavior is changed.

Although the pathways mediating Pavlovian conditioned suppression are not known, it is possible that projections from $\mathrm{CE}$ to the ventral tegmental area (VTA) are involved (Phillipson 1979; Wallace et al. 1989, 1992). The VTA is the main source of dopaminergic inputs to the nucleus accumbens (NA), and dopamine release in NA by these fibers is believed to play a crucial role in the reward processes that maintain instrumental behavior (for a review of three such models, see Nader et al. 1997). Thus, it is possible that environmental signals processed by the amygdala might regulate instrumentally rewarded behavior by way of projections from CE to VTA. Indirect evidence in support of this comes from studies showing that amphetamine, a dopamine agonist, infused into NA increases food-rewarded behavior (Everitt and Robbins 1992) and damage to CE blocks this effect (Robledo et al. 1996). In this view, an aversive CS inhibits instrumental behavior by altering processes in the neural system controlling reward-maintained behavior. This is somewhat reminiscent of so-called two-process theories, which propose that an aversive CS inhibits instrumental behavior because it leads to a motivational state (aversion) that interacts with the appetitive state elicited by reward (Konorski 1948; Rescorla and Solomon 1967; Estes 1969; Millenson and de Villiers 1972). This in turn decreases the motivation to pursue food.

In summary, the findings that lesions of the PAG block freezing but not conditioned suppression is evidence against the response competition theory of conditioned suppression. Further research should thus consider motivational interpretations of conditioned suppression. These data also suggest that there are multiple distinct mechanisms that can inhibit behavior.

\section{Acknowledgments}

This research was supported in part by the National Institute of Mental Health (grant 2R37 MH38774 to J.E.L.) and a Human Frontiers of Science Fellowship (to K.N.). The work was also supported by a grant from the W.M. Keck Foundation to New York University.

The publication costs of this article were defrayed in part by payment of page charges. This article must therefore be hereby marked "advertisement" in accordance with 18 USC section 1734 solely to indicate this fact.

\section{References}

Blanchard, C.D. and R.J. Blanchard. 1972. Innate and conditioned reactions to threat in rats with amygdaloid lesions. J. Comp. Physiol. Psychol. 81: 281-290.

Blanchard, R.J. and D.C. Blanchard. 1969. Crouching as an index of fear. J. Comp. Physiol. Psychol. 67: 370-375.

Bolles, R.C. and A.C. Collier. 1976. The effect of predictive cues on freezing in rats. Anim. Learn. Behav. 4: 6-8.

Bouton, M.E. 1994. Conditioning, remembering, and forgetting. J. Exp. Psychol.: Anim. Behav. Processes 20: $219-231$.

Bouton, M.E. and R.C. Bolles. 1980. Conditioned fear assessed by freezing and by the suppression of three different baselines. Anim. Learn. Behav. 8: 429-434.

Campeau, S. and M. Davis. 1995. Involvement of the central nucleus and basolateral complex of the amygdala in fear conditioning measured with fear-potentiated startle in rats

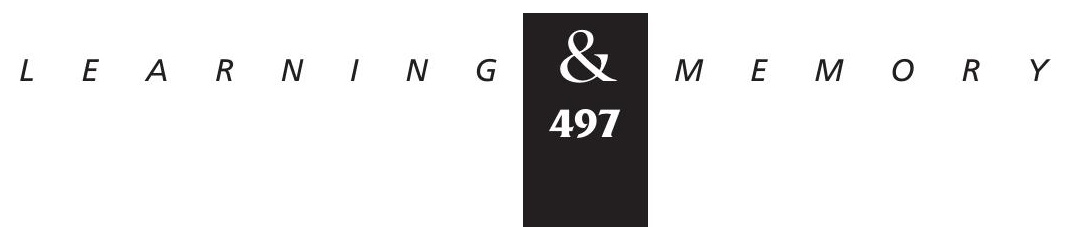




\section{Amorapanth et al.}

trained concurrently with auditory and visual conditioned stimuli. J. Neurosci. 15: 2301-2311.

Davis, M. 1994. The role of the amygdala in emotional learning. Intl. Rev. Neurobiol. 36: 225-266.

De Oca, B.M., J.P. DeCola, S. Maren, and M.S. Fanselow. 1998. Distinct regions of the periaqueductal gray are involved in the acquistion and expression of defensive responses. J. Neurosci. 18: 3426-3432.

De Toledo, L. and A.H. Black. 1966. Heart rate: Changes during conditioned suppression in rats. Science 152: 1404-1406.

Estes, W.K. 1969. Outline of a theory of punishment. In Punishment and aversive behavior (ed. B.A. Campbell and R.M. Church). pp. 57-82. Appleton-Century-Crofts, New York, NY.

Estes, W.K. and B.F. Skinner. 1941. Some quantitative properties of anxiety. J. Exp. Psychol. 29: 390-400.

Everitt, B.J. and T.W. Robbins 1992. Amygdala-ventral striatal interactions and reward-related processes. In The amygdala: Neurobiological aspects of emotion, memory and mental dysfunction (ed. J.P. Aggleton), pp. 401-430. Wiley, New York, NY.

Fanselow, M.S. 1991. The Midbrain periaqueductal gray as a coordinator of action in response to fear and anxiety. In The midbrain periaqueductal grey matter: Functional, anatomical and immunohistochemical organization (ed. A. Depaulis and R. Bandler), pp. 151-174. Plenum Publishing Corp., New York, NY.

Halpern, M. 1968. Effects of midbrain central gray matter lesions on escape-avoidance behavior in rats. Physiol. Behav. 3: $171-178$.

Kamin, L.J. 1965. Temporal and intensity characteristics of the conditioned stimulus. In Classical conditioning (ed. W.F. Prokasy), pp. 118-147. Appleton-Century-Crofts, New York, NY.

Kapp, B.S., R.C. Frysinger, M. Gallagher, and J. Haselton. 1979. Amygdala central nucleus lesions: Effect on heart rate conditioning in the rabbit. Physiol. Behav. 23: 1109-1117.

Killcross, S., T.W. Robbins, and B.J. Everitt. 1997. Different types of fear-conditioned behavior mediated by separate nuclei within amygdala. Nature 388: 377-380.

Kim, S.D., S. Rivers, R.A. Bevins, and J.J.B. Ayers. 1996. Conditioned stimulus determinants of conditioned response form in Pavlovian fear conditioning. J. Exp. Psychol. Anim. Behav. Proc. 22: 87-104.

Konorski, J. 1948. Conditioned reflexes and neuron organization. Cambridge University Press, Cambridge, UK.

LeDoux, J.E. 1995. Emotion: Clues from the brain. Annu. Rev. Psychol. 46: 209-235.
1996. The emotional brain. Simon and Schuster, New York, NY.

LeDoux, J.E., J. Iwata, P. Cicchetti, and D.J. Reis. 1988. Different projections of the central amygdaloid nucleus mediate autonomic and behavioral correlates of conditioned fear. J. Neurosci. 8: 2517-2529.

LeDoux, J.E., P. Cicchetti, A. Xagoraris, and L.M. Romanski. 1990a. The lateral amygdaloid nucleus: Sensory interface of the amygdala in fear conditioning. J. Neurosci.

10: 1062-1069.

LeDoux, J.E., C.F. Farb, and D.A. Ruggiero. 1990b. Topographic organization of neurons in the acoustic thalamus that project to the amygdala. J. Neurosci. 10: 1043-1054.

Liebman, J.M., D.J. Mayer, and J.C. Liebeskin. 1970. Mesencephalic central gray lesions and fear-motivated behavior in rats. Brain Res. 23: 353-370.

Lyon, M. 1964. The role of the central midbrain structures in condioned responding to aversive noise in rat. J. Com. Neurol. 122: 407-429.

Marks, I. 1987. The development of normal fear: A review. J. Child Psychol. Psychiatry 28: 667-697.

Mascagni, F., A.J. McDonald, and J.R. Coleman. 1993. Corticoamygdaloid and corticocortical projections of the rat temporal cortex: A phaseolus vulgaris leucoagglutinin study. Neuroscience 57: 697-715.

Mast, M., R.J. Blanchard, and C. Blanchard. 1982. The relationship of freezing and response suppression in a CER situation. Psychol. Rec. 32: 151-167.

McAllister, W.R. and D.E. McAllister 1971. Behavioral measurement of conditioned fear. In Aversive conditioning and learning (ed. F.R. Brush), pp. 105-179. Academic Press, New York, NY.

McKernan, M.G. and P. Shinnick-Gallagher. 1997. Fear conditioning induces a lasting potentiation of synaptic currents in vitro. Nature 390: 607-611.

Millenson, J.R. and P.A. de Villiers 1972. Motivational properties of conditioned anxiety. In Reinforcement: Behavioral analyses (ed. R.M. Gilbert and J.R. Millenson), pp. 97-129. Academic Press, New York, NY.

Morgan, M.A., L.M. Romanski, and J.E. LeDoux. 1993. Extinction of emotional learning: Contribution of medial prefrontal cortex. Neurosci. Lett. 163: 109-113.

Muller, J., K.P. Corodimas, Z. Fridel, and J.E. LeDoux. 1997. Functional inactivation of the lateral and basal nuclei of the amygdala by muscimol infusion prevents fear conditioning to an explicit CS and to contextual stimuli. Behav. Neurosci. 111: 683-691.

Nader, K., A. Bechara, and D. van der Kooy. 1997.

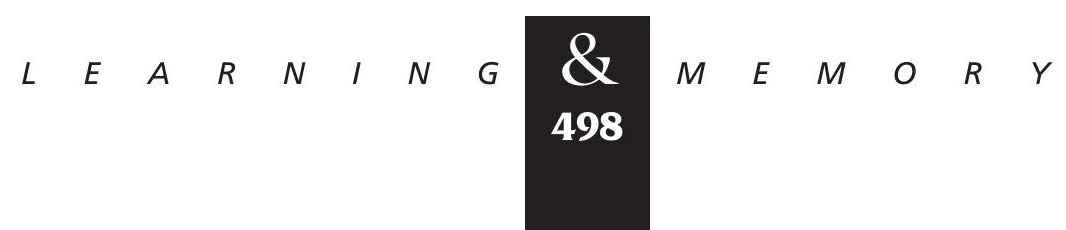


Neurobiological constraints on behavioral models of behavior. Annu. Rev. Psychol. 48: 85-114.

Phillips, R.G. and J.E. LeDoux. 1992. Differential contribution of amygdala and hippocampus to cued and contextual fear conditioning. Behav. Neurosci. 106: 274-285.

Phillipson, O.T. 1979. Afferent projections to the central tegmental area of Tsai and intrafascicular nucleus: A horseradish peroxidase study in the rat. J. Comp. Neurol. 187: 117-143.

Pitkänen, A., V. Savander, and J.L. LeDoux. 1997. Organization of intra-amygdaloid circuitries: An emerging framework for understanding functions of the amygdala. Trends Neurosci. 20: 517-523.

Quirk, G.J., J.C. Repa, and J.E. LeDoux. 1995. Fear conditioning enhances short-latency auditory responses of lateral amygdala neurons: Parallel recordings in the freely behaving rat. Neuron 15: 1029-1039.

Rescorla, R.A. and R.L. Solomon. 1967. Two process learning theory: Relationships between Pavlovian conditioning and instrumental learning. Psychol. Rev. 74: 151-182.

Robledo, P., T.W. Robbins, and B.J. Everitt. 1996. Effects of excitotoxic lesions of the central amygdaloid nucleus on the potentiation of reward-related stimuli by intra-accumbens amphetamine. Behav. Neurosci. 110: 981-990.

Rogan, M., U. Staubli, and J. LeDoux. 1997. Fear conditioning induces associative long-term potentiation in the amygdala. Nature 390: 604-607.

Romanski, L.M. and J.E. LeDoux. 1993. Information cascade from primary auditory cortex to the amygdala: Corticocortical and corticoamygdaloid projections of temporal cortex in the rat. Cereb. Cortex 3: 515-532.

Romanski, L.M., J.E. LeDoux, M.C. Clugnet and F. Bordi. 1993. Somatosensory and auditory convergence in the lateral nucleus of the amygdala. Behav. Neurosci. 107: 444-450.

Roozendaal, B., J.M. Koolhaas, and B. Bohus. 1991. Central amygdala lesions affect behavioral and autonomic balance during stress in rats. Physiol. Behav. 50: 777-781.

Thompson, J.B. and J.S. Schwartzbaum. 1964. Discrimination behavior and conditioned suppression (CER) following localized lesions in the amygdala and putamen. Psychol. Rep. 15: 587-606.

Turner, B. and M. Herkenham. 1991. Thalamoamygdaloid projections in the rat: A test of the amygdala's role in sensory processing. J. Comp. Neurol. 313: 295-325.

Walker, D.L. and M. Davis. 1997. Double dissociation between the involvement of the bed nucleus of the stria terminalis and the central nucleus of the amygdala in startle increases produced by conditioned versus unconditioned fear. J. Neurosci. 17: 9375-9383.
Wallace, D.M., D.J. Magnuson, and T.S. Gray. 1989. The amygdalo-brainstem pathway: Selective innervation of dopaminergic, noradrenergic and adrenergic cells in the rat. Neurosci. Lett. 97: 252-258.

Wallace, D.M., D.J. Magnuson, and T.S. Gray. 1992. Organization of amygdaloid projections to brainstem dopaminergic, noradrenergic, and adrenergic cell groups in the rat. Brain Res. Bull. 28: 447-454.

Received July 7, 1999; accepted in revised form August 25, 1999. 


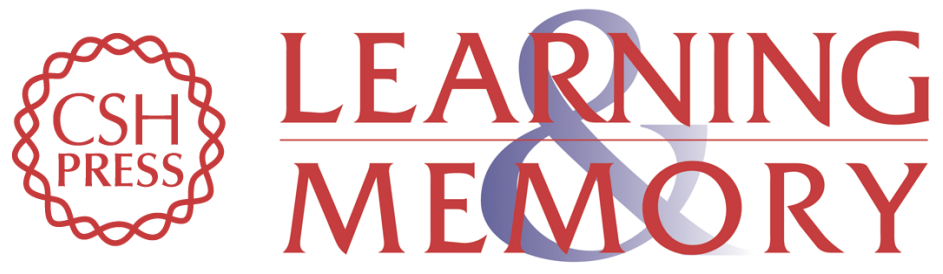

\section{Lesions of Periaqueductal Gray Dissociate-Conditioned Freezing From Conditioned Suppression Behavior in Rats}

Prin Amorapanth, Karim Nader and Joseph E. LeDoux

Learn. Mem. 1999, 6:

Access the most recent version at doi:10.1101//m.6.5.491

References This article cites 40 articles, 7 of which can be accessed free at: http://learnmem.cshlp.org/content/6/5/491.full.html\#ref-list-1

License

Email Alerting

Receive free email alerts when new articles cite this article - sign up in the box at the Service top right corner of the article or click here. 